\title{
The dynamic model for the sustainable development of the domestic tourism in the Russian Federation
}

\author{
Tatyana Kirillova $^{1 *}$, Irina Zhilinkova ${ }^{1}$, Svetlana Golovkina ${ }^{1}$, and Alla Finko ${ }^{1}$ \\ ${ }^{1}$ Peter the Great St. Petersburg Polytechnic University, Saint-Petersburg, Polytechnicheskaya str., 29, \\ Russia
}

\begin{abstract}
The article examines the role of the tourism industry in creating new jobs in the regions and increasing the welfare of the population. The multiplicative effect of the tourism industry is expressed in the active development of related sectors of the national economy. The spillover effect of tourism spending on the region's economy can be estimated using an "input-output" model. The paper provides an algorithm for determining the impact of changes in tourism spending on gross output by industry, income and employment in the region. Studies have shown that the development of tourism in St. Petersburg leads to an uneven formation of output, income and employment in various sectors of the region's economy. The development of the concept of sustainable tourism development should be based on an assessment of the socio-economic state and prospects for the development of the tourism industry. The methodology, which includes an assessment of the resource and throughput potential, is most fully consistent with the principles of the concept of sustainable tourism development. Application of the World Bank methodology for the development of the adjusted net savings index. It allows you to internalize the external costs of economic activity associated with negative impacts on ecosystems and public health, which are an underestimated value in models of sustainable tourism development. The combination of this methodology with traditional multifactor models for assessing the level of tourism development will allow a more targeted approach to the choice of mechanisms and objects of state regulation at the regional levels within the framework of indicative planning.
\end{abstract}

\section{Introduction}

Use In 2019, in the rating of the competitiveness of the tourism and travel industry of the World Economic Forum (WEF), Russia rose by 4 points, taking 39th place out of 140 countries of the world. This, of course, should generally be seen as a positive trend. However, in terms of priority given to the development of tourism and travel in the activities of the government, Russia still holds 86th place. According to the WEF, Russia also has a weak competitive position in environmental sustainability (82nd place), development of the

\footnotetext{
* Corresponding author: kirillova tan@,rambler.ru
} 
business environment (92nd), in the field of protection and safety (98th place), tourism policy and favorable conditions for travel (105th place) [1]. Despite numerous studies of recent decades devoted to this topic and highlighting the obvious benefits of developing domestic tourism in the Russian Federation, in many potentially attractive regions of Russia the tourism industry is in its infancy.

The key reasons that hinder the development of this sphere in the Russian Federation, first of all, are the lack of domestic investment in the development of the industry and the lack of modern tourism infrastructure:

- transport logistics-huge distances and the lack of convenient transfers, the lack of interregional routes;

- hotel logistics-lack of room stock, restaurant infrastructure.

On the cost price of the Russian tourist product in 2014-2020. the following internal economic factors had a negative impact:

- growth due to taxes and fees, utility tariffs and administrative barriers;

- significant decline in the real disposable income of Russians over the past 5 years. (fig. 1)

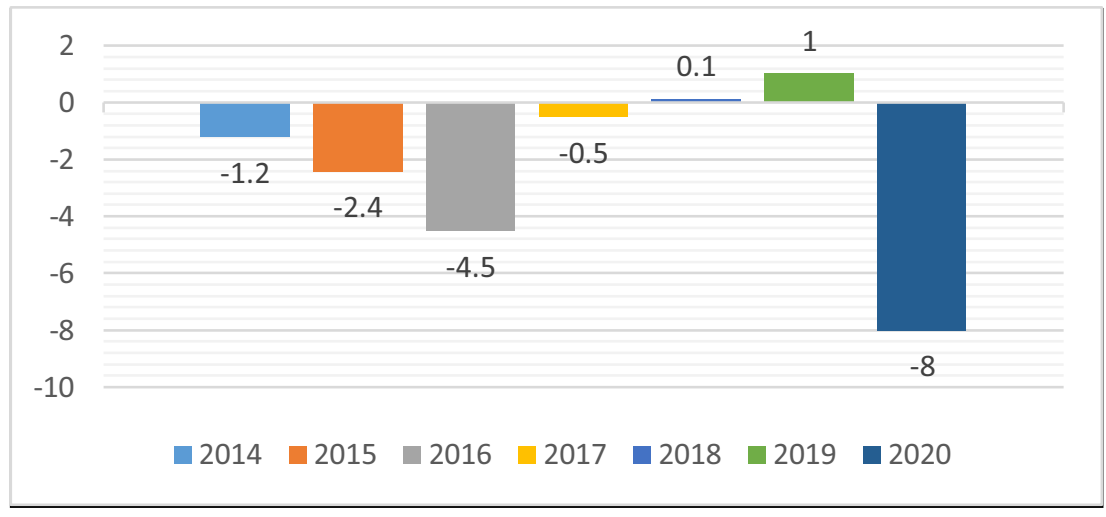

Fig. 1. Dynamics of real disposable income, in \%\% compared to the previous year [2].

Serious foreign economic destabilizing factors that indirectly increase the cost of the Russian tourist product are:

- according to the expert estimates of the Association of Tour Operators (ATOR), it decreased by $35-40 \%$ due to the introduction of quarantine measures in connection with the COVID-19 pandemic, Rosturizm estimates the total losses of the Russian tourism industry for 2020 in the amount of more than 1.3 trillion rubles [3];

- changes in the consumer behavior of Russian tourists (a decrease in confidence in official travel companies and an increase in the share of independent tourism, an increase in consumer requirements for the level of service, comfort and safety, a focus on the formation of unique tourist products, spontaneity of decision-making).

Thus, due to the above-mentioned reasons, according to experts-practitioners, on average, there are 0.4 trips per Russian citizen per year, the real share of domestic tourism in the EAP of the Russian Federation according to optimistic estimates is 5.5-6\% (This is taking into account all tourist operations in the unobserved sector of the economy), according to pessimistic estimates, the share of domestic tourism in the Russian Federation does not exceed 1-3\% [4]. 


\section{Materials and methods}

It is generally accepted that the tourism industry contributes to the creation of new jobs in the regions and increases the level of well-being of the population, since thanks to the multiplier effect, a mechanism for the active development of related sectors of the national economy is launched. The multiplier effect associated with domestic tourism is that an initial impulse is created in the form of an inflow of funds in the form of an increase in monetary incomes of the population and firms, revenues to state, regional and local budgets. The secondary impact is assessed using the concept of a multiplier. The tourist multiplier can be thought of as the ratio of changes in the Gross Regional Product (GRP) to changes in tourist spending. The output multiplier relates a unit of tourism expenditure to the final increase in output in the economy. The income multiplier shows the relationship between a unit of additional travel expenses and the final change in the level of income in a given region, which may entail these costs. The employment multiplier characterizes the number of jobs created by additional spending by tourists.

When describing the effect of the economic impact of one of the economic sectors on others, the "input-output" model proposed by V. Leontiev is used. This model is applicable not only to the analysis of intersectoral proportions, but with its help it is possible to assess the so-called secondary effect of tourism spending on the region's economy. The "inputoutput" approach focuses on the interdependencies between sectors that exist in an economy. The flexibility of the "input-output" structure makes it possible to design a model that would meet the needs of a particular region. (fig. 2.).

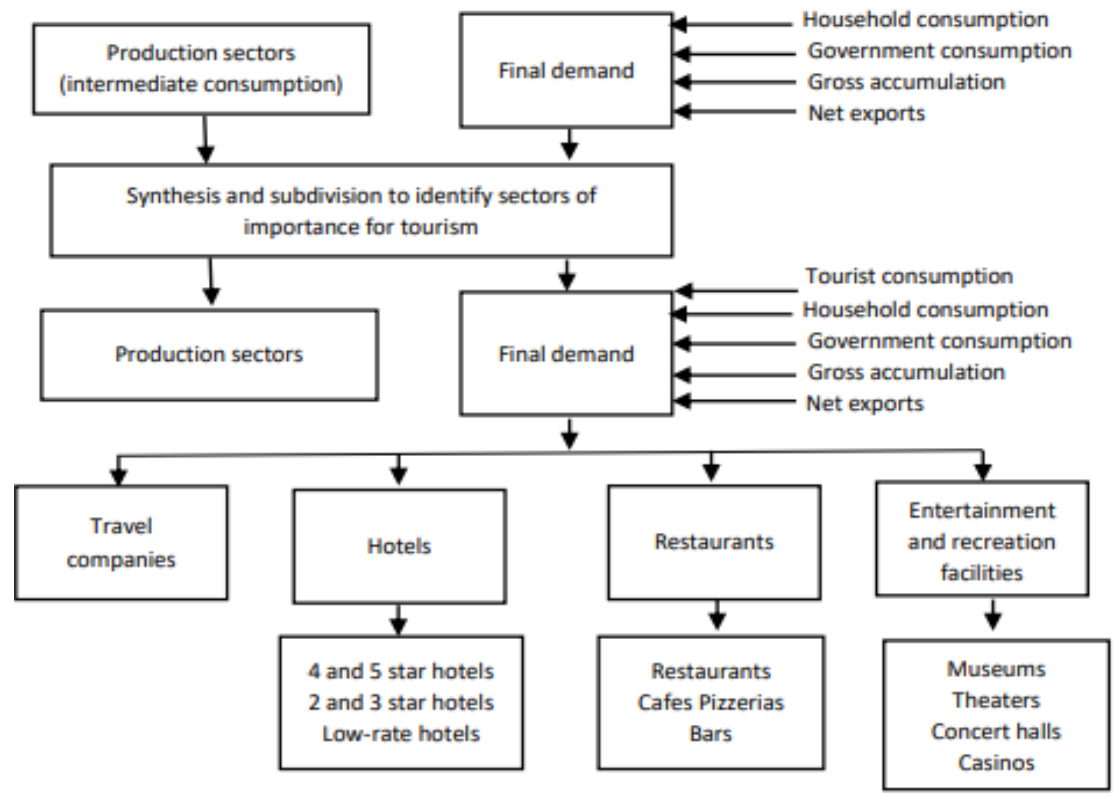

Fig. 2. Structure of the "input-output" model with the allocation of tourism industries.

The "input-output" model, which takes into account the impact of tourism on the regional economy, can be implemented based on the following algorithm:

- to build an economic and mathematical model of "input-output" of the regional economy;

- for a given composition of final outputs, make calculations of gross outputs for the analyzed period;

- to form a matrix of coefficients of direct and total material costs; 
- get the values of the coefficients of direct and total material costs;

- to form a structure and calculate the size of the components of final demand with the allocation of non-production sectors that ensure the functioning of tourism;

- to calculate the multipliers of output, income and employment for the sectors of the nonproduction sphere that ensure the functioning of tourism;

- to analyze the impact of changes in tourism spending on gross output by industry, income and employment in the region.

\section{Results}

The subject of research in this work was the city of St. Petersburg. The tourism business plays an important role in the city's economy. Both domestic tourism and inbound tourism are well developed, and their rates have dropped sharply during the COVID-19 pandemic. A feature of the tourist site is the belonging of the nearest suburbs, such as Pushkin, Pavlovsk, Peterhof, Strelna, Kronstadt, Lomonosov, to the composition of St. Petersburg.

Studies carried out according to the above algorithm for St. Petersburg showed the following results [9].

Table 1. Values of output, income and employment multipliers by region (St. Petersburg).

\begin{tabular}{|c|c|c|c|}
\hline $\begin{array}{c}\text { Destinations } \\
\text { of final } \\
\text { demand }\end{array}$ & $\begin{array}{c}\text { Output } \\
\text { multipliers }\end{array}$ & $\begin{array}{c}\text { Income } \\
\text { multipliers }\end{array}$ & $\begin{array}{c}\text { Employment } \\
\text { multipliers }\end{array}$ \\
\hline $\begin{array}{c}\text { Travel } \\
\text { companies }\end{array}$ & 2,36 & 1,03 & 0,029 \\
\hline Hotels & 2,61 & 1,17 & 0,051 \\
\hline Restaurants & 2,49 & 1,15 & 0,039 \\
\hline $\begin{array}{c}\text { Entertainment } \\
\text { and recreation } \\
\text { facilities }\end{array}$ & 2,42 & 1,14 & 0,032 \\
\hline
\end{tabular}

It follows from the table that the development of tourism in St. Petersburg leads to an uneven formation of output, income and employment in various sectors of the region's economy.

The highest multiplier of output, income and employment was calculated for the hotel sector $(2.61 ; 1.17 ; 0.051$, respectively). The second highest multiplier of output, income and employment was found for the restaurant sector $(2.49 ; 1.15 ; 0.039$, respectively). The hospitality and restaurant sectors appear to have stronger interdependent effects than other sectors that support tourism in the region. The results obtained indicate that tourism has a significant impact on the macroeconomic indicators of the economy of St. Petersburg, therefore, investments of the public and private sectors in tourism projects are required.

Tourism and hotel infrastructure remain a priority area of economic activity in St. Petersburg. Major hotel operators in the St. Petersburg market are Carlson Rezidor Hotel Group, Inter Continental Hotels Group, Sokos Hotels, AZIMUT Hotels, Marriott International, Astoria and others.

Currently investment activities in the city are carried out within the framework of regional State programs such as:

- The State Program of the Russian Federation "Development of Culture and Tourism" for 2013-2020, approved by Government Resolution No. 317 of 15.04.2014,

- The State program of St. Petersburg "Development of the sphere of culture in St. Petersburg", approved by the decree of the Government of St. Petersburg of 17.06.2014 No. 488 , 
- Strategy of the State cultural Policy for the period up to 2030, approved by the decree of the Government of the Russian Federation No. 326-r of 29.02.2016 and the St. Petersburg Strategy for the Preservation of Cultural Heritage (approved by the Decree of the Government of St. Petersburg No. 1681 of 01.11.2005).

Nevertheless, despite the abundance of programs, the only major investment project being implemented today (the volume of investments is 3.2 billion rubles) this is the reconstruction and operation of the object of cultural heritage of federal significance "Konyushennoe Department", located at the address: St. Petersburg, Konyushennaya pl., 1.

For such a significant historical and cultural center in the Russian Federation as St. Petersburg, such a scale of investment activity in this sector is clearly not enough.

In fairness, it should be noted that given the investment in tourism-related areas (primarily in transport, hotel business), the situation does not look so hopeless. The transport and logistics complex of St. Petersburg accounts for up to $20 \%$ of the total investment. The city remains one of the most attractive regions for investors.

At the St. Petersburg International Economic Forum and the Annual Investment Forum, trends in the investment policy of St. Petersburg are determined.

One of the most effective tools for stimulating investment activity, along with the mechanism of public-private partnership and the "single window" principle when supporting an investment project, is the mechanism for assigning strategic status to investment projects. The corresponding amendments to the city law "On Strategic Investment Projects, Strategic Investors and Strategic Partners of St. Petersburg" were adopted in 2017. The threshold amount of total investment that allows you to get the status of a strategic investor in the hotel business was reduced to 1 billion rubles. The position of a strategic investor significantly simplifies the procedure for registering the lease of land owned by the state. The strategic investor gets the right to

- for the lease of land plots for the construction of a hotel without bidding and at a reduced rate of up to $1.5 \%$ of its cadastral value;

- for the purchase of the plot after the completion of construction with a significant discount (preferential adjustment factor of 0.25 ).

The most promising investment projects in the tourism sector that will help restore and develop the industry affected by COVID-19 in St. Petersburg:

- Postal Quarter-An Initiative of the Russian Post. Creation of a pedestrian and recreational zone, a museum space, a congress hall, and a concert hall on the territory of 25 hectares;

- Innovative quarter on Vasilievsky Island. An initiative with Sberbank;

Landscape and architectural concept of the park "Tuchkov Buyan";

- Project "Thirty-Three Signs". The Manege initiative is in partnership with the ARKI Creative Workshop and the HSE - Saint Petersburg School of Design, with the participation of the Saint Petersburg Foundation for Innovation and Youth Initiatives.

Thus, the investment potential of the tourism industry in St. Petersburg is far from being exhausted, and in the post-pandemic period, this industry has every chance to become a driver of the socio-economic development of the region.

\section{Discussion}

The development of the tourism sector as one of the underestimated drivers of economic growth in the Russian Federation is becoming one of the strategic state tasks of the current moment. The tourism development strategy 2035, approved in 2019, presupposes, first of all, the creation of conditions for the formation and promotion of a competitive tourist product in the domestic and international markets, which should ultimately strengthen Russia's position in international rankings. The basic concepts underlying this long-term state 
program, such as "supporting infrastructure", "tourist infrastructure", "ecological capacity of the tourist territory", designed to contribute to the implementation of the set goals, are consistent with the concept of sustainable tourism development $[2,6,8]$.

The concept of sustainable tourism development was formulated at the end of the 20th century. It presupposes the achievement of positive effects of the functioning of the tourism sector when using the ecological, economic and socio-cultural resources of the host territories. In addition to the goals of economic growth, the main focus is on the tasks of neutralizing the negative consequences of the development of the tourism sector (overtourism): the destruction of the culture of the host territories, the growing discontent of the local population towards tourists, provoking social tension in the region, environmental pollution, aggravation of the problem of waste disposal and household garbage; a decrease in the attractiveness of natural landscapes and the destruction of cultural and recreational objects of tourist attention, due to vandalism and excessive anthropogenic load, transport problems). Thus, achieving the growth of socio-economic well-being through the development of tourism in the regions is impossible without preserving the quality of the living environment. [8]

The implementation of this concept requires additional monetary and financial and labor resources, which must be spent for these purposes both at the macro level and at the micro level. In this regard, the Russian Federation is faced with the task of effectively allocating limited resources allocated for the development of tourism, in conditions of deficit due to external shocks, the main of which are sanctions against the Russian Federation and the coronavirus pandemic, budgets. One of the prerequisites for fulfilling this task is the development of dynamic models of sustainable tourism development, taking into account regional specifics, as well as the coordination of specific socio-economic mechanisms to minimize all of the above costs of the tourism industry.

To achieve this goal, you should initially assess the level of tourism development in the regions, highlight the key investment objects that help stimulate the tourism industry in Russia.

\section{Conclusion}

A methodology for measuring sustainable development is in its infancy. One of the most popular approaches to assessing the socio-economic state and prospects for the development of the tourism industry among the authors is the rating approach based on the index method. Among the foreign rankings, one should highlight the rankings of countries based on the Travel \& Tourism Competitiveness Index 2019 (TTCI), calculated by the World Economic Forum, the Regional Competitiveness Index proposed by Denchu A.R., the Sustainable Tourism Development Index, Kurt S., Konakoglu B., Index of sustainable tourism development Azizi H. Among domestic researchers, the works of Velichkina A.V., (Index of tourism infrastructure), Kotelnikov D.A. stand out. (Index of Sustainable Tourism Development), Poroshina O.V. (Indicator of economic efficiency of the functioning of the tourism sector) [7]. Most of the proposed models are based on a multicriteria approach aimed at identifying socio-economic factors in tourism development and mainly indicators of economic efficiency.

From our point of view, the most fully consistent with the principles of the concept of sustainable tourism development is a methodology that includes an assessment of the resource and bandwidth potential. In this regard, the application of the World Bank's methodology for the development of the adjusted net savings index (ANSI), calculated as the ratio of adjusted net savings to GRP. It allows you to internalize the external costs (externalities) of economic activity associated with negative impacts on ecosystems and public health is an underestimated value in models of sustainable tourism development. The 
combination of this methodology with traditional multifactor models for assessing the level of tourism development will allow a more targeted approach to the choice of mechanisms and objects of state regulation at the regional levels within the framework of indicative planning.

The indicator adjusted net savings for the regions of the Russian Federation (ANS) is, in fact, an indicator of the country's national wealth, which includes the amount of natural, human and physical (created) capital minus the depletion of non-renewable and excessive use of renewable natural resources. At the same time, investment in human capital, for example, education costs, are viewed as investments that contribute to the growth of national wealth.

where

$$
A N S=G F-I A-D N R-D C E P+E H C+E P C+A S P N A,
$$

GF - gross fixed capital formation;

IA - investments in fixed capital under the activity "Mining";

DNR - deterioration of natural resources;

DCEP - damage caused by environmental pollution;

EHC - budget expenditure on human capital development;

EPC - environmental protection costs;

ASPNA - assessment of specially protected natural areas. [7]

The process of forming a system of indicators for sustainable tourism development, adapted to the socio-economic needs and resource capabilities of a particular region, should take into account the very high socio-economic differentiation of Russian regions. For the conditions of the Russian Federation, despite its attractiveness, the idea of creating a unified, comprehensive program for sustainable development is equally effective, for example, for the tourist zone of the Russian North and the Azov-Black Sea tourist zone, it is difficult to implement [10-13].

The adopted state and regional systems of indicators of sustainable tourism development, from our point of view, must necessarily take into account, first of all, the state and dynamics of development of the supporting and recreational tourism infrastructure. Because the business climate in the industry depends on its availability and condition. In most of the proposed models, the state of the infrastructure is assessed by 2-3 items, most often by the indicators of transport infrastructure.

Thus, the implementation of the concept of sustainable tourism development will be facilitated by the improvement of methods for constructing multifactor dynamic models of regional development of the tourism industry, taking into account:

- the action of multiplier effects from the development of domestic tourism on the sectors of the national economy;

- the influence of negative externalities on the development of the regional economy and providing methods for their neutralization;

- individualization of the selected indicators, taking into account regional specifics [15];

- the state and dynamics of the recreational tourist infrastructure, as the main condition for the development of the entire recreational and tourist cluster.

In general, in the modern domestic literature, there are not enough complex works devoted to the development of methods for assessing the impact of tourism on the sectoral development of the region. Carrying out such studies for the Russian Federation is very important at the present time, as it helps to plan both the development of tourism and the economy of the region as a whole. 


\section{References}

1. The Travel \& Tourism Competitiveness Report 2019. URL:

https://www.weforum.org/reports/the-travel-tourism-competitiveness-report-2019.

2. Bulletin on current trends in the Russian economy. URL: https://ac.gov.ru/uploads/2Publications/rus_feb_2020.pdf

3. Strategy for the Development of Tourism in the Russian Federation until 2035. URL: https://www.russiatourism.ru/contents/otkrytoe_agentstvo/strategiya-razvitiya-turizmav-rossiyskoy-federatsii/strategiya-razvitiya-turizma/strategiya-razvitiya-turizma-vrossiyskoy-federatsii-v-period-do-2035-goda/

4. Official website of the Association of Tour Operators of Russia. URL: https://www.atorus.ru/news/press-centre/new/53770.html

5. The reasons for the stagnation of Russian tourism are named. URL: https://www.vzsar.ru/news/2020/09/30/nazvany-prichiny-stagnacii-rossiyskogotyrizma.html.

6. O.A. Bunakov, N.A. Zaitseva, A.A. Larionova, A.D. Chudnovskiy, M.A. Zhukova, V.A. Zhukov, Journal of Sustainable Development, 8 (6), 39-44 (2015) doi: 10.5539/jsd.v8n6p39.

7. E. A. Fedorova, L. I. Chernikova, A. E. Pastukhova, Economy, 1, 16, 105 (2020)

8. S. N. Bobylev, V. S. Minakov, S. V. Solovyova, V. V. Tretyakov. Ecological and economic index of the regions of the Russian Federation. Methodology and indicators for the calculation (Moscow, 2012)

9. A.V. Finko, Metod "input-output" as a method of measuring the economic impact of tourism, in Proceedings of the International Conference, SPb: SPbSPU. (2001)

10. O.A. Bunakov, N.A. Zaitseva, A.A. Larionova, M.A. Morozova, N.V. Dmitrieva. Espacios 39(22), 2 (2018)

11. V. Bogolyubov, S. Bogolyubova, A. Malinin, A. Tanina. Sustainable development and new tourism ethics. Proceedings of the 33rd International Business Information Management Association Conference, IBIMA 2019: Education Excellence and Innovation Management through Vision 2020. (2019)

12. A. Tanina, O. Zaborovskaia, S. Tschelkina. Features of the formation of the tourist brand of the municipal formation. Proceedings of the 32nd International Business Information Management Association Conference, IBIMA 2018 - Vision 2020: Sustainable Economic Development and Application of Innovation Management from Regional expansion to Global Growth. (2018)

13. V. Bogolyubov, S. Bogolyubova, A. Malinin, A. Tanina. Formation of a new view of ecological tourism. Proceedings of the 32nd International Business Information Management Association Conference, IBIMA 2018 - Vision 2020: Sustainable Economic Development and Application of Innovation Management from Regional expansion to Global Growth 2018-November. (2018)

14. O. Zaborovskaia, T. Kudryavtseva , E. Zhogova, International Journal of Engineering and Advanced Technology, 9(1) (2019)

15. V.A. Degtereva, O.V. Zaborovskaia, E.E. Sharafanova. Methodology of targeted support for service sector enterprises in regional economic system. Proceedings of the 31st International Business Information Management Association Conference, IBIMA 2018: Innovation Management and Education Excellence through Vision 2020. (2018) 